\title{
Assessment of the competitiveness of countries as a tool to increase the sustainability of their socio-economic development
}

\author{
Askar Mustafin*1[0000-0002-8249-1223], Jaroslav Gonos 20000-0002-5708-7982], \\ Nataliya Seliverstova ${ }^{10000-0001-5146-2502]}$, and Margarita Maksimova ${ }^{30000-0003-3309-2215]}$ \\ ${ }^{1}$ Kazan Federal University, 420012 Kazan, Russia \\ ${ }^{2}$ University of Prešov, 08001 Prešov, Slovakia \\ ${ }^{3}$ Kazan State Medical University, 420012 Kazan, Russia
}

\begin{abstract}
The competitiveness of individual economies belongs to the issues frequently discussed among experts as it is closely connected with and reflects the economic situation in different countries. The focus of the present article is the survey of the development of competitiveness of selected economies and the subsequent comparison thereof. In order to further specify this focus, we concentrated on the economies of the Russian Federation and Germany. These economies are regarded as strong and efficient global economies that put emphasis on continuous growth. The economy of the Slovak Republic was selected as the secondary focus of the article as it is an open economy cooperating with major economic players, including the countries representing the subject of this article. The key criterion for the evaluation of the development was the Global Competitiveness Index and the monitored period was 2008-2017. The article contains two basic parts; the first part represents a theoretical framework of the discussed topic and the second part provides the comparison and confrontation of competitiveness in the selected economies. The final part of the article contains the identification of potential weaknesses and strengths of the evaluated economies.
\end{abstract}

Keywords. Competitiveness, economic growth, Global Competitiveness Index (GCI), sustainability, socio-economic development.

\section{Introduction}

\subsection{Problem statement}

With increasing openness and integration, the more intensive emphasis is increasingly being put on comparing not only individuals or companies (these topics are well described in the scientific literature, for example according to N. Grigoryeva [1], M. Tsuji et al. [2] but also countries and their economies. The issues regarding competitiveness do not concern only the global economies, i.e., major players in the field of economy [3], but also smaller economies.

\footnotetext{
*Corresponding author: mustafin.ksu@yandex.ru
} 
According some investigations, the main concern of policy makers in developed and developing countries today is national competitiveness and how competitiveness can be improved $[4,5]$.

This topic is substantiated and important with regard to the directions that individual economies are heading, as well as their current status. It is therefore required and necessary for each country to discuss these issues.

Currently, there is no unified system for measuring the competitiveness of individual economies, which could be used as a universal and comprehensive evaluation tool. Individual countries carefully monitor their position in multiple rankings of global economies that compare their competitiveness as it often reflects their economic status and points out their strengths as well as weaknesses. The main purpose of the present article is to concentrate on the development of competitiveness in the Russian Federation and Germany - two major economic players, on the basis of the Global Competitiveness Index. In order to extend the main idea, the survey also covered a smaller economy, in particular, Slovakia.

The economy of the Slovak Republic is an open economy; its economic efficiency and competitiveness depend on cooperation with other economies. The time interval for the survey of the development of competitiveness was 10 years, from 2008 to 2017. On the basis of the obtained results, we presented the identification and evaluation of the weaknesses and strengths of the selected economies. Although one aspect of the significance of the issues discussed herein is to understand the development of the monitored competitiveness indicators in individual countries, the other, very important aspect is to know the weaknesses of the monitored economies, which need to be eliminated in the future.

\subsection{Competitiveness}

The concept of competitiveness is a significant category in economic analysis. There are many different approaches to assessing the competitiveness of individuals [6], enterprises, regions, and countries. Competitiveness is influenced by a large number of factors, ranging from institutions, market forces [7], to such particular factors as opportunistic behavior [8] or the level of development of social capital. A nation's competitiveness is determined by the capacity of its industry to innovate in all spheres [9].

The history of competitiveness evaluation dates back to 2004. Since then, the World Economic Forum has been using the model of the Global Competitiveness Index (GCI) to rank the countries depending on the level of their competitiveness. This highly comprehensive index, used for the measurement of competitiveness of individual countries, takes into account the microeconomic as well as macroeconomic bases of a nation's competitiveness. It defines competitiveness as the set of institutions, policies and factors that determine the level of productivity of a country. The level of productivity, in turn, sets the level of prosperity that can be reached by an economy. In other words, more competitive economies are able to produce higher wages for their citizens. Low wage level does not stimulate a person to active actions, intensive labor, and even to self-improvement [10]. The level of productivity also determines the return on investment to the national economy. With regard to the fact that the rates of return represent the key determinants of the economic growth rate, economies with a higher level of competitiveness are those which usually grow faster in the medium to long term [11].

The question of theoretical description of competitiveness at the macroeconomic level is therefore only considered in connection with the development of globalisation processes in the global economy, in particular with regard to the growth of competition among individual countries or global economic centres. The corresponding research is focused primarily on correlations between international competitiveness and economic growth or the standard of 
living. In the present globalised world, competitiveness represents one of the most frequently assessed characteristics of national economies.

When assessing competitiveness from the macroeconomic point of view, economies are evaluated on the basis of their qualities and ability to compete internationally, their economic power, status and conditions in which they exist; this shows a special development and is of special importance after a country joins the EU.

The term competitiveness belongs to frequently used expressions. However, it is not an unambiguous term. On the contrary, competitiveness is associated with a large number of different approaches and various definitions. For many political players, competitiveness is a term they often use to defend their political strategies that intervene with the structure of their economies. Some authors warn that this term should be used carefully because placing too much emphasis on competitiveness is more likely to have a negative impact on the national economy. This is determined by the fact that the term as such does not have a strong general meaning; it is only important when comparing different competitors. On the other hand, when the issues regarding competitiveness are dealt with carefully, it may potentially stimulate positive processes [12].

Competitiveness of individual nations is a relatively novel economic concept which became more intensively discussed as late as in the 1980s. However, it is based on the conventional political economy, especially on the theory of comparative advantages [13].

\section{Methods}

\subsection{Economic growth}

Important factors that form the competitiveness of an economy include the power of undertakings, depending on a particular industry in which they produce, performance values of their products, production costs, and the level of technological processes used in the production process, as well as the development of national infrastructure, etc.

Competitiveness of an economy is also affected by other business-related factors, such as reliability and trustworthiness of undertakings, quality of their production, demand for their products, energy efficiency [14], the ability of undertakings to respond flexibly to the required changes etc., which are often difficult to quantify. The level of development of small and medium entrepreneurship directly determines the degree of development of the country's economy as a whole [15].

Competitiveness of a country may also be affected by certain factors that are difficult to measure, such as reliability and trustworthiness of a country, protectionism, its stability and domestic political climate as well as the ability to achieve various sustainable development goals [16] that can be achieved through different economic business models. The current rise of protectionism has become the main uncertainty associated with global energy, economy, and the environment [17]. Some researchers [18, 19]in recent years develop more effective approaches towards to economic growth without emission growth.

The Gross Domestic Product (GDP) is used to identify the economic efficiency of a country and it is a largely and most frequently used indicator when interpreting the advancement degree of an economy, the standard of living of the population, development intensity, as well as the changes in these indicators within a certain period of time.

The Gross National Product (GNP represents a monetary value of all final goods and services produced during a certain period, for example, one year by national producers, both in the country and abroad.

From the macroeconomic point of view, there is an increasing trend of regarding statistically significant indicators, identified applying the regression analysis, as the key 
factors. The most important ones include the bases of the competitive advantage and the related technological level of the production process, innovation ability, costs of research and development, as well as, for example, the trustworthiness of the police, willingness to delegate authorities, etc. Probably the most examined indicators are unit labour costs and the actual exchange rate.

According to the winner of the Nobel Prize for economy, Simon Kuznetz, economic growth may be characterised as a fast growth of GNIper capita and of productivity of production factors which may be expressed as the ratio of the total amount of production to the quantity of work and capital, i.e., the production growth per one unit of labour, or capital, as well as fast structural transformation of an economy which is currently characteristic with the transformation from industry to services and from electronic to microelectronic and information nature of the economy, and also as the fast changes in the overall social nature of an economy and the growth of important ethical, moral and secularisation principles, or the on-going process of convergence and divergence of economies in developed and developing countries.

In modern society, a person's life is inextricably related to their professional activities [20]. Recent investigations show a complex relationship between economic growth and a large number of qualitative factors that have an impact on the quality of human capital, such as the level of education, cognitive skills of the population [21], the level of social capital [22], etc. But due to the complexity of quantifying such factors in this article, we consider economic growth as an increase in the real potential product over a certain period of time. It is expressed as a change in potential flow parameters, such as GNP or GDP, over a certain period of time. Economic efficiency may be assessed in the long as well as short terms. In the long term, it represents real economic growth of a potential product. In the short term, it is a growth of the actual product.

\subsection{Global Competitiveness Index}

The World Economic Forum (WEF) is an organisation that annually, since 1979, issues the Global Competitiveness Report (GCR) evaluating the factors of permanent economic growth and long-term prosperity of economies in individual countries. Competitiveness is currently an integral indicator that reflects country adapts to global challenges too, such as digitalization, extend of service economy, etc. It is important, because Digitalisation can boost the transformation towards a more sustainable circular economy [23].

The Global Competitiveness Index is a generally accepted tool used for the evaluation of the potential of a particular country to generate growth. Through a comparison of numerous countries in the world, it provides a review of the advantages of each compared country on the global scale. The ranking of the countries is based on combining the publicly available data [24].

The bases consist of 12 pillars of competitiveness, divided into three groups. The first group includes the basic requirements. The pillars assigned to this particular group include institutions, infrastructure, and health and primary education. These pillars are crucial for the factor economy.

Each economy is able to produce the wealth of the country. When interconnected with the competitiveness, with the gross domestic product representing the basic part of the economic productivity, it facilitates simple confrontation at the international level. However, this is accompanied by a small problem - it does not provide a sufficient image of the quality achieved by the given economy. In terms of measuring the competitiveness, the gross domestic product is not particularly specific because it lacks numerous sections which should form its bases. Also, increasing productivity is not always the best choice within the country's political strategy.

Baláž [25] defines the term «competition» using the Global Competitiveness Index as it describes certain competition among the subjects operating on the market. Every subject 
pursues their own interests related mainly to the sale of services and products. Thus, we can talk about a certain form of competition based on the competitiveness principle.

The GCI captures the openness of criteria which are correlated and, at the same time, not in conflict. The evaluation is based on the weighted average of multiple components; each one reflecting a different aspect of the complex reality, also referred to as the competitiveness. All components are divided into 12 individual pillars - referred to as the 12 pillars of competitiveness. These criteria are correlated and have direct mutual impacts; for example, Pillar 12 - Innovation cannot be achieved with a lower education degree (Pillar 5), or it is not possible to create innovations with inefficient markets (Pillars 6 and 7). Even though individual criteria are interconnected, a country's competitiveness may also be assessed on the basis of each individual criterion. With each criterion, the country is assessed using the 1-to-7 scale, 7 being the best score according World Economic Forum [26].

\section{Results}

\subsection{Economic efficiency of selected countries as to the Gross National Product}

The relevant macroeconomic indicators of the state of individual economies include the Gross National Product which reflects the size and power of an economic system; in addition, the changes thereof over a certain period of time facilitate the identification of potential economic impacts. The graph below represents the development of the Gross National Product for the monitored countries.

GNI, PPP (current international \$)

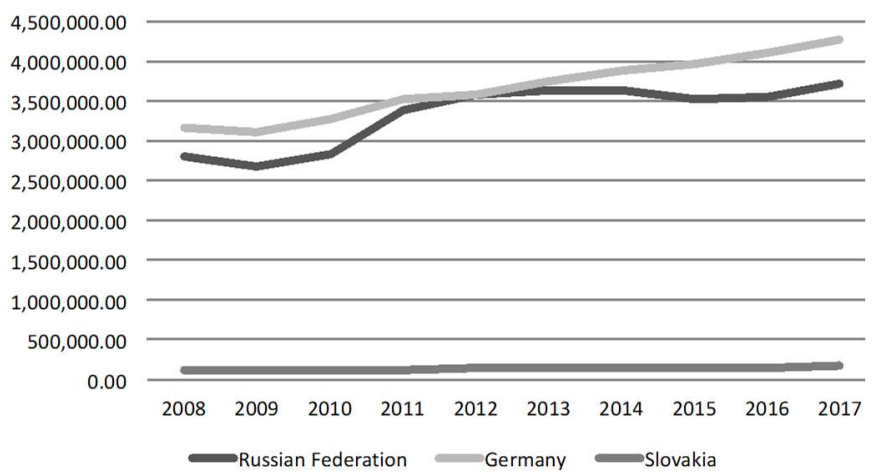

Fig. 1. GNI (PPP) of selected countries. Source: Own elaboration according to used literature.

The graphical representation shows the trend in the development of the GNP within the period from 2008 to 2017 in the Russian Federation, Germany and Slovakia. The main comparison described in the article is focused on two large economies, the economy of the Russian Federation and the economy of Germany. The trend of these two economies, as may be seen in the graph, shows a growing tendency which is also confirmed by the percentage changes presented in the table below. Positive development of the Gross National Product proves that these large economic systems are capable of efficient and flexible response to various external effects which acquire a geopolitical context. The trend in the development of GNI of the Russian Federation is characterised with a higher fluctuation and instability, unlike the trend in Germany. Partially identified imbalances are associated with the multiscriptual nature of the Russian economy and its territorial extent, as well as historical conditions (in particular, with the territorial distribution of infrastructure with its centralization in the capital) 
[27]. Both economies exceeded the level of USD 3,500,000 billion. This confirms that these two economic systems are efficient. As for the percentage changes, the comparison of the values of the GNI, as an economic indicator, at the beginning of the monitored period, in 2008, and at the end, in 2017, did not show any significant deviations. As for the Russian Federation, the change represented $25 \%$ while for Germany it was $26 \%$.

Table 1. Percentage Change of GNI of selected countries. Source: Own elaboration.

\begin{tabular}{|c|c|c|}
\hline \multicolumn{3}{|c|}{ Percentage Change of GNI (2008-2017) } \\
\hline Russian Federation & Germany & Slovakia \\
\hline $25 \%$ & $26 \%$ & $26 \%$ \\
\hline
\end{tabular}

The secondary comparison included the economy of the Slovak Republic. The trend in the development of the GNI, as an economic indicator, shows a growing tendency. As mentioned above, the economy of Slovakia represents a small player in this comparison and economies of the Russian Federation and Germany represent big economy players, as confirmed by the values of the GNI indicator. In other words, Slovakia was included in this comparison because it is a small, open economy and its economic nature is largely related to the economic status of large economic players.

\subsection{Comparison of competitiveness based on the GCI}

The Global Competitiveness Index (GCI) aims to measure the factors that determine productivity because this has been found to be the main determinant of long-term growth.

Table 2. Global Competitiveness Index of selected countries. Source: Own elaboration according to used literature.

\begin{tabular}{|c|c|c|c|c|c|c|}
\hline \multirow{2}{*}{ Year } & \multicolumn{7}{|c|}{ Global competitiveness index } \\
\cline { 2 - 7 } & Russian Federation & \multicolumn{2}{c|}{ Germany } & \multicolumn{2}{c|}{ Slovakia } \\
\cline { 2 - 7 } & Value & Rank & Value & Rank & Value & Rank \\
\hline $2007-2008$ & 4,19 & 58 & 5,51 & 5 & 4,45 & 41 \\
\hline $2008-2009$ & 4,31 & 51 & 5,46 & 7 & 4,40 & 46 \\
\hline $2009-2010$ & 4,15 & 63 & 5,37 & 7 & 4,31 & 47 \\
\hline $2010-2011$ & 4,24 & 63 & 5,39 & 5 & 4,25 & 60 \\
\hline $2011-2012$ & 4,21 & 66 & 5,41 & 6 & 4,19 & 69 \\
\hline $2012-2013$ & 4,20 & 67 & 5,48 & 6 & 4,14 & 71 \\
\hline $2013-2014$ & 4,225 & 64 & 5,51 & 4 & 4,10 & 78 \\
\hline $2014-2015$ & 4,37 & 53 & 5,49 & 5 & 4,15 & 75 \\
\hline $2015-2016$ & 4,44 & 45 & 5,53 & 4 & 4,22 & 67 \\
\hline $2016-2017$ & 4,51 & 43 & 5,57 & 5 & 4,28 & 65 \\
\hline
\end{tabular}

Germany is the largest economy of the euro area and ranks among the largest global economies (following the USA, China, India and Japan). History proves that it definitely sets the pace and direction of the development of the entire continent. Good macroeconomic indicators, stable tax environment and high competitiveness of local companies make the German economy a clear European number 1 . When confronted with the economies of the Russian Federation and Slovakia, in terms of the GCI development, it clearly holds a leading position in the monitored period. The competitiveness of Germany shows stable development, as proved by its positions in the ranking where only a little fluctuation was observed. The development of the index values of the Russian economy reflects a positive trend because the monitored index values are increasing; this is also reflected in a higher position in the ranking by the GCI. 
Table 3. Percentage Change of GCI of selected countries. Source: Own elaboration.

\begin{tabular}{|c|c|c|}
\hline \multicolumn{3}{|c|}{ Percentage Change of GCI (2008-2017) } \\
\hline Russian Federation & Germany & Slovakia \\
\hline$+7 \%$ & $+1 \%$ & $-4 \%$ \\
\hline
\end{tabular}

In terms of competitiveness, the Russian Federation showed the highest percentage difference, i.e., a $7 \%$ change in the GCI over the period from 2008 to 2017. This change brought the Russian Federation position number 46 in the ranking. The observations showed that the economic crisis in 2008 and its aftermath affected the final GCI values in individual economies and it also affected their competitiveness in the last years. Slovakia showed a 4\% decrease in the GCI value during the monitored period. Slovakia reached the lowest score in the evaluation of the goods market efficiency, with the gain of 55.00 value; this was only enough for the $78^{\text {th }}$ position, with Singapore being the leader in terms of the GCI. As for the monitored area, the Russian Federation holds the $83^{\text {rd }}$ position and within this miniconfrontation Germany holds the $7^{\text {th }}$ position.

Germany fell one position down as compared to the last year of the survey and its total score slightly decreased. Nevertheless, the excellent efficiency of the German economy in Innovation and Business Sophistication is especially remarkable. Germany and its innovation potential and macroeconomic environment have been assessed as the best at the global level, supported by a high level of technological readiness and high-quality infrastructure. In addition, Business Sophistication holds the second position, right behind the USA, in terms of GCI values development; this confirms the high efficiency of this economy.

Table 4. 12 Pillars of GCI of selected countries. Source: Own elaboration according to used literature.

\begin{tabular}{|c|l|c|c|c|}
\hline № & \multicolumn{1}{|c|}{ Factor } & Russian Federation & Germany & Slovakia \\
\hline 1 & Institutions & 52,7 & 73,5 & 56,4 \\
\hline 2 & Infrastructure & 72,2 & 90,2 & 77,6 \\
\hline 3 & Macroeconomic enviroment & 87,5 & 100,0 & 99,9 \\
\hline 4 & Health and primary education & 68,5 & 94,5 & 84,0 \\
\hline 5 & Higher education and training & 68,5 & 85,4 & 68,6 \\
\hline 6 & Goods market efficiency & 54,2 & 72,0 & 55,0 \\
\hline 7 & Labor market efficiency & 59,5 & 74,1 & 60,2 \\
\hline 8 & Financial market development & 54,8 & 80,2 & 63,7 \\
\hline 9 & Technological readiness & 72,1 & 69,3 & 67,8 \\
\hline 10 & Market size & 84,0 & 85,8 & 57,7 \\
\hline 11 & Business sophistication & 62,9 & 81,6 & 64,5 \\
\hline 12 & Innovation & 50,7 & 87,5 & 46,6 \\
\hline
\end{tabular}

The Russian Federation ( $\left.38^{\text {th }}\right)$ improved its status in five positions, mostly driven by the macroeconomic environment (up 38 positions to $53^{\text {rd }}$ ), rebounding strongly from the $2015-$ 16 recession. Russia is a developing country, which for two decades has passed the stage of the formation of a new civilizational model [28]. However, its economy remains highly dependent on mineral exports and the prospects remain uncertain. Weak links continue to include the financial market $\left(107^{\text {th }}\right)$, in particular, the banking sector, along with the aspects of institutional quality, such as property rights $\left(106^{\text {th }}\right)$, judicial independence $\left(90^{\text {th }}\right)$, and corruption which remains one of the most problematic factors for doing business there. Russia has passed new laws aimed at increasing the minimum wage (2015) and protecting temporary employment (2016) which have lower labour market flexibility $\left(75^{\text {th }}\right.$, down 18 positions). The reliance on the international experience, taking into account certain features of the Russian economy, will help to avoid protracted crises and unfavourable circumstances [29]. 


\section{Pillars of GCl}

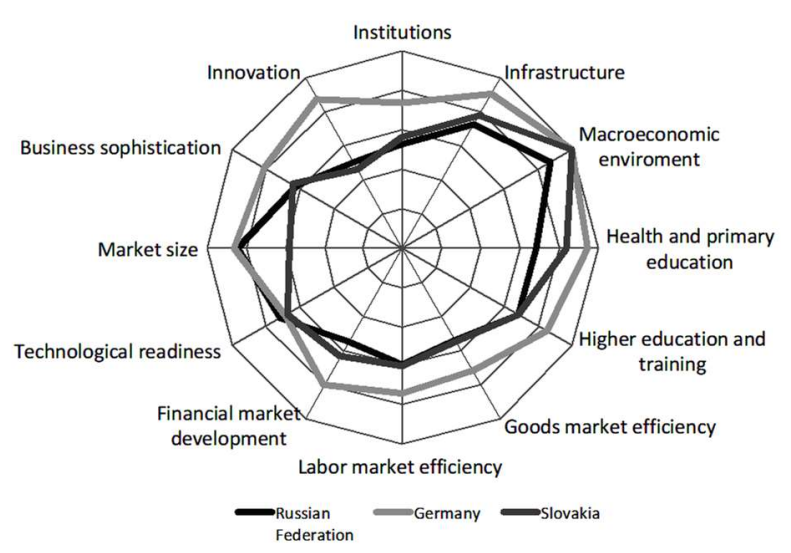

Fig. 2. 12 Pillars of GCI of selected countries. Source: Own elaboration according to used literature.

Germany is the largest and the most powerful economy in Europe. On a global scale, it is now the fourth largest economy according to the nominal GDP. The German economy is known for exporting machinery, cars, home appliances, and chemicals. Germany possesses highly qualified labour force but its economy will have to face multiple challenges in the following years, including Brexit and the immigration crisis. The value of the nominal GDP of Germany reached the amount of 3.42 billion dollars while its GDP at purchasing power parity represents 4.13 billion dollars. German GDP (at PPP) per capita represents 49814 dollars. Over the last years, the economy of this country was slowly growing in $1-2 \%$ and this trend is expected to continue. Germany is excellent as to the innovation capacity. However, its innovation capacity is only one of the twelve pillars forming together the overall competitiveness of the country's economy. As Germany is currently the fourth largest economy, it achieves high values especially for health, infrastructure and stability.

WEF does not yet include digital transformation, or factors related to data analysis, in the list of key factors affecting competitiveness. However, it is possible that such factors will be added in the future, as many researchers [30] emphasize their importance for sustainable development.

The WEF emphasises digitalisation as an important driving force; on the other hand, it clarifies that in order to achieve competitiveness, other factors must be strong too. It is now early to predict the long-term effects of increasingly protectionist policies of many countries and the globally growing populism because the ranking was based exclusively on the last year's data.

\section{Conclusion}

The World Economic Forum assesses the competitiveness of individual countries. The competitiveness index reflects the potential of a country to reach sustainable growth in the medium term. Competitiveness is an important question for most countries of the world as each economy endeavours to use its potential in the most optimal way.

The survey was carried out for selected economies of Germany, Russian Federation and Slovakia while the latter was used as an example of a small economy, trying to establish itself in a dynamically changing economic field through potential cooperation. The GCI facilitates making a certain external overview of these countries with regard to their weaknesses and strengths and the related capacity for improvement which is inevitable in the existing economic environment. 
The results of analyses and the index values give grounds to the conclusion that good results achieved in the field of knowledge economy, innovations and informatization shift economies to leading positions in terms of their competitiveness.

Our conclusions are in line with the previously obtained research results, according to which, in the current conditions of rapid technological changes and digital transformation, the importance of competitiveness at all levels of economic relations is increasing [31, 32].

So, any new and deeper knowledge in this area, in our opinion, will contribute to the growth of scientific knowledge of the theory of competitiveness and can be used to develop management actions for managing competitiveness.

\section{References}

1. N. Grigoryeva, O. Grigoryeva. The dependence of opportunistic behavior from economic growth, American Journal of Applied Sciences 12 (3), 222-228 (2015). DOI: 10.3844/ajassp.2015.222.228.

2. M. Tsuji, Y. Ueki, H. Shigeno, H. Idota, T. Bunno. $R \& D$ and non-R\&D in the innovation process among firms in ASEAN countries: based on firm-level survey data, European journal of management and business economics 27 (2), 198-214 (2018). DOI: 10.1108/EJMBE-02-2018-0030.

3. B. Sofrankova, D. Kiselakova, V. Cabinova. Innovation as a source of country's global competitiveness growth, SHS Web of Conferences 39, 1-11 (2017). DOI: 10.1051/shsconf/20173901026.

4. M.M. Khyareh, N. Rostami. Macroeconomic Conditions, Innovation and Competitiveness, J Knowl Econ (2021). DOI: 10.1007/s13132-021-00752-7.

5. K. Schwab. The global competitiveness report, World Economic Forum 671, (2017).

6. D. Urbig, W. Bönte, J. Schmutzler, A. Curcio, V. Andonova. Diverging associations of dimensions of competitiveness with gender and personality, Personality and Individual Differences 176, 767-775 (2021). DOI: 10.1016/j.paid.2021.110775.

7. C. Ketels. Michael Porter's Competitiveness Framework - Recent Learnings and New Research Priorities, Journal of Industry Competition and Trade 6 (2), 115-136 (2006). DOI: $10.1007 / \mathrm{s} 10842-006-9474-7$.

8. R.M. Kundakchyan, N.S. Grigoryeva. The influence of the opportunistic behaviour on the contractual relationship, Journal of Economics and Economic Education Research 17 (1), 68-73 (2016). DOI: 10.4172/2375-4389.1000298.

9. N. Popadynets, O. Yakymchuk, A. Yakymchuk, R. Bilyk. Increasing Competitiveness of Economic Regions: Prospects for Innovative Development, Intelligent Human Systems Integration, 496-502 (2021). DOI: 10.1007/978-3-030-68017-6_74.

10. A.N. Mustafin, O.A. Ignateva. Formation of the Human Capital Assessment Quality Model at the Present Stage of Development of Innovative Economy, Academy of Strategic Management Journal 15 (1), 27-37 (2016). DOI: 10.2307/257098.

11. ProIN Časopis pre stredný a vrcholový manažment, Globálny index konkurencie schopnosti 2013-2014 6 (3), (2013).

12. J. Wilson. Territorial Competitiveness and Development Policy, http://www.tips.org.za/ files/Wilson_James_Paper.pdf(2008).

13. S. Garelli, Competitiveness of nations: The Fundamentals, http://www.imd.ch/ documents/wcc/content/fundamentals.pdf (2006).

14. A. Mills, J. Dong, L. Yiling, M. Baafi, B. Li, K. Zeng. Towards sustainable competitiveness: How does financial development affect dynamic energy efficiency in Belt \& Road economies? Sustainable Production and Consumption 27, 587-601 (2021). DOI: 10.1016/j.spc.2021.01.027. 
15. M.D. Khafizov, A.N. Mustafin. Development of Small and Medium Entrepreneurship: Evidence from Russia, International Journal of Economic Perspectives 11 (3), 1529-1534 (2017). DOI: 10.29228/ijbemp.44683.

16. K. Govindan, K.M. Shankar, D. Kannan. Achieving sustainable development goals through identifying and analyzing barriers to industrial sharing economy: A framework development, International Journal of Production Economics 227, (2020). DOI: 10.1016/j.ijpe.2019.107575.

17. Q. Wang, F. Zhang. The effects of trade openness on decoupling carbon emissions from economic growth - Evidence from 182 countries, Journal of Cleaner Production 279, (2021). DOI: 10.1016/j.jclepro.2020.123838.

18. Q. Wang and S. Wang. Is energy transition promoting the decoupling economic growth from emission growth? Evidence from the 186 countries, J. Clean. Prod 260, (2020). DOI: 10.1016/j.jclepro.2020.120768.

19. Q. Wang, F. Zhang. Does increasing investment in research and development promote economic growth decoupling from carbon emission growth? An empirical analysis of BRICS countries, J. Clean. Prod 252, (2020). DOI: 10.1016/j.jclepro.2019.119853.

20. I.A. Rudaleva, A.N. Mustafin. The Impact of Stress Stability on Job Satisfaction and the Quality of Human Capital, Journalof History Cultureand Art Research, 6 (5), 333-341 (2017). DOI: 10.7596/taksad.v6i5.1252.

21. E.A. Hanushek, L. Woessmann. Education, knowledge capital, and economic growth, The Economics of Education (Second Edition) 14, 171-182 (2020). DOI: 10.1016/B9780-12-815391-8.00014-8.

22. J. Halme. The role of social capital in the institutionalization of regional place marketing activity, Place Branding and Public Diplomacy Journal, (2021). DOI: 10.1057/s41254021-00201-x.

23. M. Antikainen, T. Uusitalo, P. Kivikytö-Reponen. Digitalisation as an Enabler of Circular Economy, Procedia CIRP 73, 45-49 (2018). DOI: 10.1016/j.procir.2018.04.027.

24. N.A. Sarkar. Enhancing Global Competitiveness: Advantage India, (2009).

25. P. Baláž, A. Hamara, G. Sopková. Konkurencieschopnost' a jej význam v národnej ekonomike: zmeny a výzvy v období globálnej finančnej krízy, Bratislava: Sprint, (2015). DOI: 10.1051/shsconf/20219209018.

26. World Economic Forum «The global competitiveness report 2017-2018», Geneva: World Economic Forum (2017).

27. N.S. Seliverstova, A.N. Mustafin, E. Benková. Analysis of the Factors Affecting the Choice of Information Systems by Economic Subjects of Russian Federation, Journal of Social Sciences Research 5, 46-51 (2018). DOI: 10.32861/jssr.spi5.46.51.

28. A.N. Mustafin, A.E. Shlyakhtin, R. Kotulič. Role of Public Management in Elimination Regional Disparities, Polish Journal of Management Studies 1 (19), 260-270 (2019). DOI: 10.17512/pjms.2019.19.1.20.

29. A.A. Vasilova, A.N. Mustafin, A.V. Morozov. The Analysis of Russian Population Incomes for 2012-2015, HELIX 8 (1), 2935-2940 (2018). DOI: 10.29042/2018-2935-2940.

30. M-L. Tseng, R.R. Tan, A. Chiu, Ch. Chien, T. Kuo. Circular economy meets industry 4.0: Can big data drive industrial symbiosis? Resources, Conservation and Recycling 131, 146-147 (2018). DOI: 10.1016/j.resconrec.2017.12.028.

31. N. Seliverstova, E. Iakovleva, O. Grigoryeva. Electronic space of modernity: Some benefits and risks, Journal of Engineering and Applied Sciences 13 (16), 6799-6805 (2018). DOI: 10.36478/jeasci.2018.6799.6805.

32. G. Bressanelli, F. Adrodegari, M.Perona, N. Saccani, Exploring How Usage-Focused Business Models Enable Circular Economy through Digital Technologies, Sustainability 10, 639 (2018). DOI: 10.3390/su10030639. 